
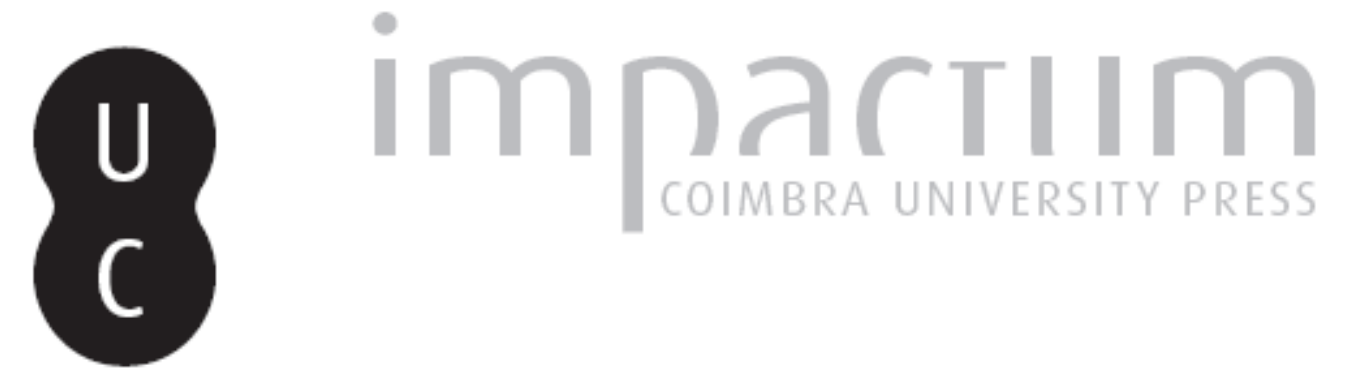

\title{
José Leite de Vasconcellos: nos caminhos de Prometeu
}

Autor(es): $\quad$ Barroso, Maria do Sameiro

Publicado por: Imprensa da Universidade de Coimbra

URL persistente:

URI:http://hdl.handle.net/10316.2/37536

DOI:

DOI:http://dx.doi.org/10.14195/0872-2110_59_12

Accessed : $\quad$ 26-Apr-2023 13:35:12

A navegação consulta e descarregamento dos títulos inseridos nas Bibliotecas Digitais UC Digitalis, UC Pombalina e UC Impactum, pressupõem a aceitação plena e sem reservas dos Termos e Condições de Uso destas Bibliotecas Digitais, disponíveis em https://digitalis.uc.pt/pt-pt/termos.

Conforme exposto nos referidos Termos e Condições de Uso, o descarregamento de títulos de acesso restrito requer uma licença válida de autorização devendo o utilizador aceder ao(s) documento(s) a partir de um endereço de IP da instituição detentora da supramencionada licença.

Ao utilizador é apenas permitido o descarregamento para uso pessoal, pelo que o emprego do(s) título(s) descarregado(s) para outro fim, designadamente comercial, carece de autorização do respetivo autor ou editor da obra.

Na medida em que todas as obras da UC Digitalis se encontram protegidas pelo Código do Direito de Autor e Direitos Conexos e demais legislação aplicável, toda a cópia, parcial ou total, deste documento, nos casos em que é legalmente admitida, deverá conter ou fazer-se acompanhar por este aviso.

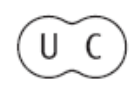


COIMBRA • 2014

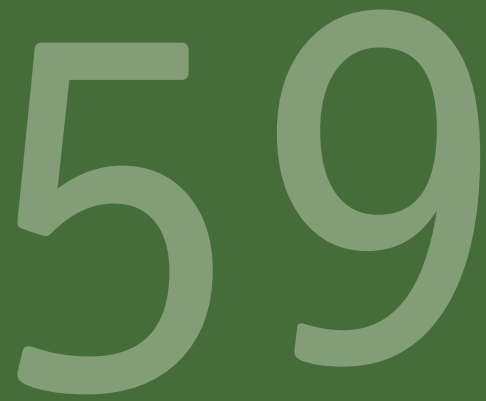

\title{
BOLETIM DE
}

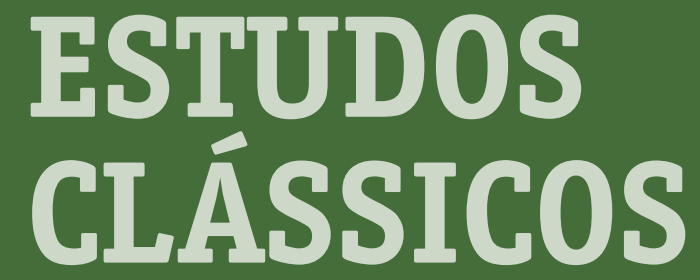

\author{
ASSOCIAÇÃO \\ PORTUGUESA \\ DE ESTUDOS \\ CLÁSSICOS \\ INSTITUTO \\ DE ESTUDOS \\ CLÁSSICOS
}




\title{
JOSÉ LEITE DE VASCONCELLOS - NOS CAMINHOS DE PROMETEU
}

\author{
(JOSÉ LEITE DE VASCONCELLOS -ON THE PATHS OF PROMETHEUS) \\ MARIA DO SAMEIRO BARROSO \\ INVESTIGADORA - MUSEU NACIONAL DE ARQUEOLOGIA
}

Resumo: Na poesia de José Leite de Vasconcellos (1858-1941), fundador do Museu Nacional de Arqueologia de Lisboa, deflagra a avidez sem limites do seu anseio de conhecimento. Esta característica que norteia a sua vida, a sua obra, e se mantém em toda a sua poética, configura a proposta de leitura deste artigo. José Leite de Vasconcellos, à luz do mito de Prometeu, é portador da chama libertária, paradigma de humanismo, na Antiguidade, mas aponta também estigmas da hybris antiga que se projectará tragicamente no século XX, no qual assistimos à desumanização e à perda de valores que desvirtuam o progresso, proporcionado pela investigação e pelos avanços da ciência, questionando a própria projecção emblemática do mito.

Palavras-chave: José Leite de Vasconcellos; mito de Prometeu; humanismo; literatura; investigação científica

\begin{abstract}
In the poetry of José Leite de Vasconcellos (1858-1941), the founder of the National Archaeological Museum of Lisbon, the boundless greed of his longing for knowledge is palpable. This trait that guides his life and work and is kept throughout his poetics sets the bid to read this article. José Leite de Vasconcellos, focused on the light of the Promethean myth, bears the libertarian flame, paradigm of humanism in Antiquity, but also points out
\end{abstract}


stigmas of the ancient hybris that will launch itself tragically in the twentieth century. This period witnesses the dehumanization and loss of values perverting the progress provided by research and the advances of science, even questioning the symbolic projection of the myth.

Keywords: José Leite de Vasconcellos; Promethean myth; humanism; literature; scientific research

José Leite de Vasconcellos (1858-1941), autor de uma obra pioneira e gigantesca nas áreas da Arqueologia, Antropologia e Filologia, expressou a sua inquietação e o seu desejo sem fim pelo saber, na sua obra poética. Esta característica está patente desde as suas primeiras publicações. No "Poema da Alma" (1879), o labor estético em torno torno da palavra alia-se à demanda do ser nos seus anseios mais altos, em busca da Verdade, procurando chegar mais longe (como numa competição desportiva), ultrapassando as metas do seu pensamento, tal como expressa na Dedicatória dessa obra:

«A vós que trabalhais, ou à luz da oficina, Ou crestados do sol, em áspera campina Entre as urzes cruéis, batidos pelo vento; A vós que vos servis da pena ou do martelo, Luzeiros do porvir, sacerdotes do belo, Atletas da palavra, heróis do pensamento» ${ }^{1}$.

No final do século XIX, a Verdade e o conhecimento científico sobrepunham-se. É a ela que José Leite de Vasconcellos aspira:

«! Ó sábios, Sonhadores do real, sim, trazei a meus lábios,

1 Vasconcellos 1879: 11. 
Não o cálix da dor, - o cálix que embriaga, Mas a verdade! É ela a estrela que me afaga!»²

Lançando-se numa aventura estética, ontológica e gnosiológica, projeta a sua voz titânica na esfera cósmica onde se desenrola o diálogo da Alma com os elementos e a Natureza: Mar, as Flores, as Aves, os Ventos, as Nuvens, o Sol, as Estrelas, situando-o nos caminhos de Prometeu. Nada detém o investigador, o cientista, o poeta, com todas as consequências que daí advêm, após a retirada do véu à deusa que só revelava a Verdade aos seus iniciados.

$\mathrm{Na}$ Antiguidade, o mito de Prometeu configurara o paradigma de humanismo e progresso. Para o poeta latino Ovídio (43 a.C.-18 d.C.), o homem é o filho de Jápeto (um dos titãs, filho de Geia, pai de Prometeu, Epimeteu e Atlas):

«Faltava ainda um ser mais sublime sublime que estes, mais capaz De conter uma alta inteligência, que pudesse reger os outros. Nasceu então o homem. Este, ou o fez de semente divina Aquele artífice do universo, a origem do mundo melhor; Ou então a terra recente, separada há pouco do alto éter, Talvez ainda contivesse sementes do céu, seu parente, terra Que o filho de Jápeto, misturando com água da chuva, Moldou à imagem dos deuses que governam tudo.» ${ }^{3}$

Este paradigma alterou-se profundamente com o Cristianismo. Até ao final do século XVIII, o homem deixou de ser o centro do mundo. Os homens de ciência tinham de enfrentar os constrangimentos e as proibições à actividade científica impostas pela Igreja que exercia a sua vigilância opressiva através da Inquisição.

2 Vasconcellos 1879: 11.

3 Ovídio vv. 77- 88 2007: 37. 
No entanto, noutra linha, a tradição esotérica antiga também impunha restrições ao conhecimento. A Verdade só devia transmitida por alegorias ou enigmas, pois aproximava-se da própria face da divindade. Essa divindade era a deusa egípcia Ísis que simbolizava a totalidade do ser. $\mathrm{Na}$ sua estátua, em Sais, segundo Plutarco e Proclo, figurava uma inscrição:

«Sou tudo o que é, foi e será. Nenhum mortal levantou o meu véu.» («Ich bin alles, was da ist, war und sein wird. Kein Sterblicher

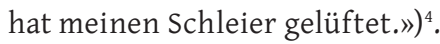

Num poema, escrito em 1795 por Friedrich Schiller, A imagem velada de Sais (Das verschleierte Bild zu Sais ${ }^{5}$ ), este tema fora abordado com mais cautela. Enquanto, no poema de Alxingers, Orfeu foi convidado a levantar o véu e a abraçar a verdade como uma amada, na balada de Schiller, o jovem sacerdote, não compreendeu que, sendo motivo de procura por parte de todos os que a ansiavam conhecer, a verdade tinha de permanecer escondida e inacessível. Durante a noite, desobedecendo ao hierofante, dirigiu-se à imagem e destapou-a, tendo sido encontrado inconsciente, junto dela, no dia seguinte e, posteriormente, mergulhado numa depressão profunda que o levou à morte.

Nunca se soube o que a divindade lhe transmitiu, sob o olhar pálido da lua daquela noite. o jovem não estava preparado para a revelação pela qual tanto ansiava.

No final do século XVIII, num poema do poeta vienense, Johann Baptist Alxingers (1755-1797), relativo à iniciação de Orfeu nos mistérios de Ísis, o jovem aproximava-se da deusa cujo rosto estava coberto pelo véu que ele retirava, abraçando-a e jurando-lhe fidelidade.

Com esta atitude, desobruía, de forma livre e desassombrada, a via para o conhecimento e para a investigação científica. Tinha passado o

4 Tradução de Assmann 2005: 118.

5 Schiller 2004: 178-189. 
tempo em que, nos grandes mistérios, o candidato era levado ao Adyton, o lugar mais sagrado do templo e completamente inacessível, no qual só podiam entrar alguns eleitos. Segundo Clemente de Alexandria era lá que guardavam a Verdade:

«Os egípcios distinguem o Logos verdadeiramente secreto, que preservam no santuário mais interior da Verdade, através do «Adyta» (quer dizer, em espaços absolutamente inacessíveis» ${ }^{6}$.

As consequências desta retirada do véu foram imediatamente entendidas. Mary Shelley (1797-1851) escreveria o prólogo “Frankenstein ou o Moderno Prometeu", da popular obra com esse título, publicado em 1818, pressentindo o perigo e o horror que as novas conquistas poderiam trazer à humanidade. No final do século XIX, Nietzsche (1844-1900) proclamara a morte de Deus.

No final do "Poema da Alma", as estrelas respondem, legitimando uma linha positivista e antropocêntrica pela qual José Leite de Vasconcellos, como homem de ciência que é, se rege:

«Alma, quem negará teu génio, teu talento?

És obra de ti mesma. E tu neste momento

Sabes onde é que estás? 0 universo dominas;

Tens por sob os teus pés as regiões divinas,

Os pélagos da luz, o raio, a tempestade,

As nuvens, os trovões, enfim,

a imensidade!

A ALMA:

«- Quero chegar ao fim,

O absoluto sondar! Quem m'o impede a mim? -»

6 «Die Ägypter kennenzeichen den wirklich geheimen Logos, den sie im innersten Heiligtum der Wahrheit bewahren, durch «Adyta» (d. h. durch absolut unbetretbare Räume)» (Clemente de Alexandria, tradução de Assmann 2005: 219).

7 Vasconcellos 1879: 24. 
Nestes versos, há, no entanto, um tom de desafio, resvalando para uma certa sobranceria, que lembra a hybris grega. o final do século XIX registara a grande explosão científica, tendo alterado profundamente a mentalidade, as estruturas sociais, os paradigmas religiosos, os padrões morais e as opções estéticas. O século XX trouxe grandes progressos à humanidade, mas também os já pressentidos horrores aos quais nem já Prometeu sobrevive.

Num poema do poeta alemão Bertoldt Brecht (1898-1965), dois dias após o lançamento da bomba atómica em Hiroshima e Nagasaki, a figura de Prometeu surge completamente desvirtuada da sua capacidade para trazer benefício e progresso aos homens, pois ele próprio entregou o fogo aos deuses, que funcionam como um coro, pois o verdadeiro poder está nas mãos dos que o exercem criminosamente, infligindo sofrimento à humanidade:

\section{(«Arbeitsjournal}

\subsection{0 .45}

erwäge einen Prometheus, die götter sind unwissend und bösartig, schlau im erpressen von opfern, lebend von den fetten des lands. Prometheus erfindet das feuer und übergibt es verbrecherweise den göttern. sie fangen und fesseln ihn. damit er nicht den menschen sein feuer ausliefern kann. von diesem feuer erfährt er lange nichts, denn sieht er rote feuersbrünste am horizont: die götter haben es benutzt, die menschen zu brandschatzen. die götter nur als chor auftretend.

Am 6. Und 9. August 1945 explodieren die Atombomben über Hiroshima und Nagasaki.» ${ }^{8}$ )

«ornal do Trabalho

2.10 .45

pensa na a figura de Prometeu, os deuses são ignorantes e

8 Brecht 1995: 165. 
viciosos, astúciosos a chantagear as vítimas, vivendo na fartura da terra. Prometeu inventa o fogo e entrega-o criminosamente aos deuses. eles prendem-no e acorrentam-no. para que ele não possa entregar seu fogo ao povo. com este fogo ele não aprende nada há muito tempo, pois vê as chamas vermelhas no horizonte: os deuses usaram-no para saquear o povo. os deuses aparecendo apenas como um coro.

A 6 de Agosto $E 9$ de Agosto de 1945, explodiram as bombas atómicas de Hiroshima e Nagasaki.»

Neste poema, os caminhos de Prometeu que José Leite de Vasconcellos e os cientistas do século XIX e XX tinham abraçado com tanto entusiasmo, tendo trazido inegáveis progressos, revelavam já o seu reverso implacável e a desumanidade do tempo em que vivemos, sem deuses nem valores.

\section{BIBLIOGRAFIA}

Assmann, J. (2005), Die Zauberflöte, Carl Hanser Verlag, München/Wien.

Brecht, B. (1995), in Wolfgang Storch/Burghard Damerau (hrsg) Mythos Prometheus, Texte von Hesiod bis René Char, Reclam Verlag, Leipzig. Ovídio (2007), Metamorfoses, tradução de Paulo Farmhouse Alberto, Lisboa, Cotovia. Schiller, F. (2004), Sämtliche Gedichte und Balladen, Insel Verlag, Frankfurt am Main. Vasconcellos, J.L. (1879), Poema da Alma, Typ. do Commercio e Industria, Porto. 